Jurnal Progres Ekonomi Pembangunan (JPEP)

Volume 4, Nomor 1 (2), Tahun 2019

Page: $27-35$

\title{
PENGARUH SISTEM INFORMASI AKUNTANSI, SISTEM PENGENDALIAN INTERN, GOOD GOVERNMENT GOVERNANCE, BUDAYA ORGANISASI TERHADAP KINERJA PT. PLN PERSERO SUB RAYON WUA-WUA DAN BENUA BENUA
}

\author{
Riswan Wiranto \\ Program Pascasarjana, Universitas Halu Oleo, Kendari \\ Emaail: riswanwiranto95@gmail.com \\ Ishak Awaluddin \\ Universitas Halu Oleo, Kendari
}

Mulyati Akib

Universitas Halu Oleo

\begin{abstract}
This study aims to determine and analyze the effect of accounting information systems, internal control systems, go od Goverment governance, organizational culture on the performance of PT PLN (Persero) Sub Rayon Wua-Wua and continents. Respondents in this study were all employees of PT PLN (Persero) Sub Rayon Wua-Wua and continents who had positions as Managers, Supervision, assistants, juniors, staff. The total respondents were 105 people. Analysis of the data used in this study is a multiple linear regression analysis technique that is processed through SPSS version 23 software.

The results of this study indicate that the $t$ value of accounting information system (X1) is 7.729 with a significance of 0,000 (tsig $=0,000$ more keci than the value of $\alpha=0.05$ thus, accounting information system variables have a significant effect on company performance. Internal Control System Variables (X2) of 2,244 with a significance level of 0,027 (tsig $=0,000$ ) Smaller than the value of $\alpha=0,05$, the internal control system variable has a significant effect on company performance. Good Corporate Governance $(X 3)$ of 2,241 with significant 0,027 (tsig $=0,000$ ) smaller than $\alpha=0.0505$, the Good Governacne variable has a significant effect on company performance. Organizational Culture variable is 6.423 with a significance level of 0.000 (tsig $=0,000$ smaller than the value of $\alpha=0.05$, the organizational culture variable has a significant effect on company performance.
\end{abstract}

Keywords: Accounting information systems, internal control systems, good goverment governance, organizational culture, performance

\section{PENDAHULUAN}

Undang-Undang Nomor 25 Tahun 2009 Pelayanan Publik adalah kegiatan atau rangkaian kegiatan dalam rangka pemenuhan kebutuhan pelayanan sesuai dengan peraturan perundangundangan bagi setiap warga negara dan penduduk atas barang, jasa, dan/atau pelayanan administratif yang disediakan oleh penyelenggaraan pelayanan publik. Penyelenggara Pelayanan Publik yang selanjutnya disebut Penyelenggara adalah setiap institusi penyelenggara negara, korporasi, lembaga independen yang dibentuk berdasarkan Undang-Undang untuk kegiatan pelayanan publik, dan badan hukum lain yang dibentuk sematamata untuk kegiatan pelayanan public. Dalam Organisasi penyelenggara pelayanan publik yang selanjutnya disebut Organisasi.

Penyelenggara adalah satuan kerja penyelenggara pelayanan publik yang berada di lingkungan institusi penyelenggara negara, korporasi, lembaga independen yang dibentuk berdasarkan undang-undang untuk kegiatan pelayanan publik, dan badan hukum lain yang dibentuk semata-mata untuk kegiatan pelayanan publik. Salah satu organisasi penyelenggara pelayanan publik yaitu Badan Usaha Milik Negara (BUMN). 
Jurnal Progres Ekonomi Pembangunan (JPEP)

Volume 4, Nomor 1 (2), Tahun 2019

Page: $27-35$

http://ojs.uho.ac.id/index.php/JPEP

Badan Usaha Milik Negara sebagai organisasi sektor public atau usaha yang sebagian besar modalnya milik negara dengan tujuan utamanya tidak mencari keuntungan keuangan melainkan untuk memberikan pelayanan dan mensejahterahkan publik.

Kinerja merupakan keluaran yang dihasilkan oleh fungsi- fungsi dan indikator suatu pekerjaan atau suatu profesi dalam waktu tertentu. Peraturan Menteri dalam Negeri Nomor 13 Tahun 2006 telah menjelaskan bahwasaanya kinerja merupakan keluaran/ hasil dari kegiatan/ program yang akan atau telah dicapai sehubungan dengan penggunaan anggaran dengan kuantitas dan kualitas yang terukur. Pencapaian kinerja perusahaan yang kompetitif, dibutuhkan peran komponen lainnya, yakni: (1) tersedianya sumber daya system informasi akuntansi; terimplementasikannya system pengendalian intern; (3) terciptanya good government governance; (4) Budaya Organisasi. Namun beberapa teori dan hasil penelitian bahwa pencapaian kinerja perusahaan tidak dipengaruhi oleh variable tersebut.

Susanto (2013) mengungkapkan bahwa sistem informasi akuntansi pada perusahaan akan mempengaruhi kinerja dalam perusahaan tersebut, baik secara langsung maupun tidak langsung. Untuk dapat meningkatkan daya saing perusahaan maka dibutuhkan sumber daya sistem informasi akuntansi. Sumber daya yang dimaksudkan adalah sumber daya material, yakni berupa perangkat pendukung terselenggaranya sistem informasi akuntansi. Selain itu, sumber daya manusia sebagai pengoperasionalisasikan sistem tersebut.

Indriawaty (2015) berpendapat bahwa sistem informasi akuntansi memiliki dampak negatif, yakni akan terdapat penurunan kinerja karyawan apabila penggunaan sistem informasi akuntansi yang terlalu rumit, disertai daya kerja karyawan yang rendah. Kinerja juga dapat dipengaruhi oleh sistem pengendalian internal. Sistem pengendalian internal merupakan serangkaian kegiatan yang dilakukan oleh perusahaan untuk memberikan keyakinan yang cukup akan tercapainya tujuan peusahaan. Perusahaan pada umumnya menggunakan sistem pengendalian internal untuk mengarahkan operasi perusahaan dan mencegah terjadinya penyalahgunaan sistem (Arsiningsih, 2015). penelitian Rubino (2017), bahwa sistem pengendalian internal tidak berpengaruh signifikan dan negative terhadap kinerja perusahaan maupun karyawa. Bambang (2012) berpendapat bahwa kinerja pemerintah daerah akan lebih baik bila diterapkan prinsip good government governance diterapkan pada pemrintah daerah. Pengolaan pemerintah yang kurang baik banyak menimbulkan dampak negatif bagi pemerintah dan masyarakat atau pihak lainnya. Contohnya adalah pemerintah akan mengalami kurangnya kepercayaan masyarakat dan akan mempertajam isu-isu krusial yang terjadi dimasyarakat. Hal ini didukung pada hail penelitian (Febrina dan Arstansi, 2017) yang menyatakan bahwa tidak terdapat pengaruh signifikan dari good government governance terhadap kinerja pemerintah daerah.

Koesmono (2005:9) berpendapat bahwa budaya dapat didefinisikan sebagai berbagai interaksi dari ciri-ciri kebiasaan yang mempengaruhi kelompok- kelompok orang dalam lingkungannya. Oleh karena itu, tidak bisa dipisahkan dengan kinerja dari sumber daya manusia yang ada di instansi tersebut. Sebuah instansi yang memiliki budaya kerja yang baik, dapat dilihat dan diamati oleh peninjauan dari luar maupun dalam instansi tersebut. Hasil penelitian ini didukung (Ida Ayu dan Agus, 2009) Hasil penelitian ini membuktikan bahwa budaya organisasi mempunyai pengaruh positif dan signifikan terhadap kinerja perusahaan, artinya budaya organisasi yang merupakan hasil dari interaksi ciri-ciri kebiasaan yang mempengaruhi kelompok-kelompok orang dalam lingkungan organisasinya, akan membentuk suatu persepsi subyektif keseluruhan mengenai organisasi berdasarkan pada faktor-faktor seperti toleransi resiko, tekanan pada tim, dan dukungan orang, persepsi keseluruhan ini akan menjadi budaya atau kepribadian organisasi tersebut yang mampu mendukung dan mempengaruhi kepuasan kerja 
Jurnal Progres Ekonomi Pembangunan (JPEP)

Volume 4, Nomor 1 (2), Tahun 2019

Page: $27-35$

http://ojs.uho.ac.id/index.php/JPEP

karyawan dan kinerja perusahaan serta dampak yang lebih besar pada budaya yang lebih kuat. Sedangkan dalam penelitian Edward (2016), menunjukan budaya organisasi secara parsial berpengaruh negatif terhadap kinerja pegawai di Dispenda Sulut UPTD Todano.

Pertentangan teori dan hasil penelitian terkait pengaruh system informasi akuntansi, sistem pengendalian intern, good government governance dan budaya organisasi terhadap kinerja PT. PLN (Persero) Sub Royon Wua-Wua dan Sub Rayon Benua-benua, jika mencermati kondisi yang sebenarnya, masih ditemukan kelemahan dalam pengimplementasian.

Berdasarkan pengamatan awal yang dilakukan oleh peneliti, ditemukan adanya beberapa permasalahan pada Sub-Rayon Wua-Wua dan Sub-Rayon Benu-Benua. Dimana ditemukan keluhan masyarakat (pelanggan) atas ketidakpuasan kinerja PLN. Tudingan banyak dikeluhkan warga adalah sistem informasi tagihan yang setiap bulan bahwa oknum PLN masih menggunakan dugaan atau rumus berdasarkan hitungan mereka. Sehingga pelanggan pascabayar merasa dirugikan dengan sistem tersebut. Temuan ini didukung dengan beberapa informasi terhadap klaim pelanggan bahwa beban pemakaian tidak sesuai dengan biaya yang dibebankan dan terindikasi petugas catat meter PLN tidak melakukan tugasnya secara baik, Standar Operasional Prosedur yang dilaksanakan oleh petugas catat-meter adalah ketika mendatangi rumah pelanggan dan terkunci maka petugas catat-meter hanya menfoto pagar tersebut dan kemudian menaksir pemakaian oleh pelanggan, kemudia ketika terjadi adanya kenaikan harga beban daya, PT. PLN (Persero) Sub-Rayon Wua-Wua dan Sub-Rayon BenuBenua, tidak menyampaikan kepada pelanggan, pemadaman listrik tanpa pemberitahun, tanpa mengenal waktu, tanpa informasi hanya dengan alasan over kapasitas, hingga banyaknya kasus penyambungan ilegal listrik, penambahan daya listrik ilegal, dan oknum-oknum perantara penyambungan listrik yang menggunakan jasa cepat pemasangan dengan pembayaran lebih dari harga standar pemasangan yang telah ditentukan oleh oknum PT. PLN( Persero) Sub Rayon WuaWua dan Benua-Benua.

Dampak dari kasus tersebut menyebakan prinsipprinsip good government governance dapat dikatakan buruk dan lemah. Penyebab semuanya adalah sistem pengendalian intern yang tidak berjalan maksimal. Begitu juga budaya organisasi yang masih lemah. Hal lainnya, terkait pegendalian intern adalah secara internal "aneh" sampai dengan hari ini baik manajer line, manajer middle bahkan manajer puncak pun tidak dapat mengatasi internal mereka terkait kasus di atas. Dan menjadi rahasia umum bahwa oknum manajer itupun ikut terlibat secara tidak langsung. Beberapa permasalahan yang terjadi pada PT. PLN tersebut, maka dibutuhkan sistem informasi akuntansi, sistem pengendalian intern, implementasi prinsip-prinsip good government governance dan budaya organisasi yang baik di dalam sebuah organisasi.

Perbedaan hasil penelitian dan fenomena serta perbedaan sudut pandang ahli maka peneliti tertarik untuk mengkaji penelitian dengan judul pengaruh sistem informasi akuntansi, sistem pengendalian intern, good government governance dan budaya organisasi terhadap kinerja PT. PLN( Persero) Sub Rayon WuaWua dan Benua-Benua.

\section{METODE PENELITIAN}

Populasi pada penelitian ini adalah seluruh karyawan PT. PLN (Persero) Subrayon Wua-Wua dan Subrayon Benu-Benua. Sebaran populasi pada dua rayon dan sebelas kantor pelayanan PT. PLN (Persero) Sub Rayon Wua-Wua dan BenuaBenua sebanyak 228 orang (baik karyawan tetap maupun karyawan tidak tetap dan kontrak).

Metode penentuan sampel dalam penelitian ini menggunakan rumus solving dengan penarikan sampel menggunakan teknik Stratified Random Sampling. Sehingga total sampel terpilih dalam penelitian ini berjumlah 112 orang. Jenis data dalam penelitian ini adalah data primer dan data sekunder. Teknik pengumpulan data dalam penelitian ini adalah angket, wawancara dan 
Jurnal Progres Ekonomi Pembangunan (JPEP)

Volume 4, Nomor 1 (2), Tahun 2019

Page: 27-35

e-ISSN: 2052-5171

http://ojs.uho.ac.id/index.php/JPEP

dokumentasi. Dalam penelitian ini, penulis menggunakan analisis statistik deskriptif dan analisis statistik inferensial untuk uji hipotesis. Adapun hipotesis yang diajukan adalah sebagai berikut :

$\mathrm{H}_{1}$ : Sistem Informasi akuntansi berpengaruh signifikan terhadap kinerja PT. PLN (Persero) Sub Rayon Wua-Wua dan Benua-benua

$\mathrm{H}_{2}$ : Sistem pengendalian intern berpengaruh signifikan terhadap kinerja PT. PLN (Persero) Sub Rayon Wua-Wua dan Benuabenua

$\mathrm{H}_{3}$ : Good government governance berpengaruh signifikan terhadap kinerja PT. PLN
(Persero) Sub Rayon Wua-Wua dan Benua-benua.

$\mathrm{H}_{4}$ : Budaya organisasi berpengaruh signifikan terhadap kinerja PT. PLN (Persero) Sub Rayon Wua-Wua dan Benua-benua.

\section{HASIL DAN PEMBAHASAN}

\subsection{Hasil penelitian}

Uji Analisis Faktor

Uji analisis faktor merupakan uji yang digunakan untuk melihat faktor mana dari indikator-indikator yang ada pada sebuah variabel yang dominan mempengaruhi terbentuknya variabel tersebut.

Tabel 1.

Rekapitulasi Analisis Perbandingan Hasil Uji Faktor dan Rata-rata Jawaban Responden

\begin{tabular}{|c|c|c|c|c|c|}
\hline Variabel & Indikator & Mean & $P C A$ & $\begin{array}{l}\text { KMO } \\
\text { MSA }\end{array}$ & Sig. \\
\hline \multirow{6}{*}{$\begin{array}{c}\text { Sistem Informasi } \\
\text { Akuntansi } \\
\left(\mathrm{X}_{1}\right)\end{array}$} & Hardware $\left(\mathrm{X}_{1.1}\right)$ & 4,38 & 0,810 & \multirow{6}{*}{0,602} & \multirow{6}{*}{0,000} \\
\hline & Software $\left(\mathrm{X}_{1.2}\right)$ & 4,32 & 0,859 & & \\
\hline & Brainware $\left(\mathrm{X}_{1.3}\right)$ & 4,50 & 0,812 & & \\
\hline & Procedure $\left(\mathrm{X}_{1.4}\right)$ & 4,00 & 0,507 & & \\
\hline & Database $\left(\mathrm{X}_{1.5}\right)$ & 3,88 & 0,504 & & \\
\hline & Communication Networking $\left(\mathrm{X}_{1.6}\right)$ & 3,91 & 0,752 & & \\
\hline \multirow{5}{*}{$\begin{array}{c}\text { Sistem } \\
\text { Pengendalian } \\
\text { Internal } \\
\left(\mathrm{X}_{2}\right)\end{array}$} & Lingkungan Pengendalian $\left(\mathrm{X}_{2.1}\right)$ & 4,45 & 0,577 & \multirow{5}{*}{0,575} & \multirow{5}{*}{0,000} \\
\hline & Kegiatan Pengendalian $\left(\mathrm{X}_{2.2}\right)$ & 4,61 & 0,820 & & \\
\hline & Informasi dan Komunikasi $\left(\mathrm{X}_{2.3}\right)$ & 4,48 & 0,660 & & \\
\hline & $\operatorname{Pemantauan}\left(\mathrm{X}_{2.4}\right)$ & 4,50 & 0,691 & & \\
\hline & Penilaian Resiko $\left(\mathrm{X}_{2.5}\right)$ & 4,47 & 0,628 & & \\
\hline \multirow{6}{*}{$\begin{array}{l}\text { Good Goverment } \\
\text { Governance }\left(\mathrm{X}_{3}\right)\end{array}$} & Rule of Law $\left(\mathrm{X}_{3.1}\right)$ & 4,45 & 0,695 & \multirow{6}{*}{0,507} & \multirow{6}{*}{0.000} \\
\hline & Keterbukaan $\left(\mathrm{X}_{3.2}\right)$ & 4,61 & 0,690 & & \\
\hline & Responsive $\left(\mathrm{X}_{3.3}\right)$ & 4,48 & 0,800 & & \\
\hline & Efektif dan Efisien $\left(\mathrm{X}_{3.4}\right)$ & 4,50 & 0,737 & & \\
\hline & Akuntabilitas $\left(\mathrm{X}_{3.5}\right)$ & 4,47 & 0,747 & & \\
\hline & Visi Strategis $\left(\mathrm{X}_{3.6}\right)$ & 4,31 & 0,585 & & \\
\hline \multirow{3}{*}{$\begin{array}{c}\text { Budaya } \\
\text { Organisasi }\left(\mathrm{X}_{4}\right)\end{array}$} & Analisis dan Stabilitas $\left(\mathrm{X}_{4 \cdot 1}\right)$ & 4,40 & 0,982 & \multirow{3}{*}{0,608} & \multirow{3}{*}{0,000} \\
\hline & $\begin{array}{l}\text { Orientasi hasil, manusia dan kelompok } \\
\left(\mathrm{X}_{4 \cdot 2}\right)\end{array}$ & 4,32 & 0,906 & & \\
\hline & $\begin{array}{l}\text { Agresivitas, Inovasi dan Manajemen } \\
\text { Resiko }\left(\mathrm{X}_{4 \cdot 3}\right)\end{array}$ & 4,50 & 0,892 & & \\
\hline \multirow{6}{*}{$\begin{array}{c}\text { Kinerja } \\
\text { Perusahaan }(\mathrm{Y})\end{array}$} & Perencanaan $\left(\mathrm{Y}_{1.1}\right)$ & 4,37 & 0,838 & \multirow{6}{*}{0,584} & \multirow{6}{*}{0,000} \\
\hline & Investigasi $\left(\mathrm{Y}_{1.2}\right)$ & 4,45 & 0,935 & & \\
\hline & Koordinasi $\left(\mathrm{Y}_{1.3}\right)$ & 4,43 & 0,525 & & \\
\hline & Evaluasi $\left(\mathrm{Y}_{1.4}\right)$ & 4,40 & 0,825 & & \\
\hline & Staffing $\left(\mathrm{Y}_{1.5}\right)$ & 4,25 & 0,624 & & \\
\hline & Representatif $\left(\mathrm{Y}_{1.6}\right)$ & 4,40 & 0,655 & & \\
\hline
\end{tabular}

sumber: Data primer diolah (2018) 
Jurnal Progres Ekonomi Pembangunan (JPEP)

Volume 4, Nomor 1 (2), Tahun 2019

Page: 27-35

http://ojs.uho.ac.id/index.php/JPEP

\section{Hasil Uji Hipotesis dan Uji MRA}

Tabel 2

Hasil Pengujian Untuk Uji Koefisien Determinasi (R Square)

\begin{tabular}{|l|r|r|r|r|}
\hline Model & $\mathrm{R}$ & $\mathrm{R}$ Square & \multicolumn{1}{|c|}{$\begin{array}{c}\text { Adjusted R } \\
\text { Square }\end{array}$} & $\begin{array}{c}\text { Std. Error of the } \\
\text { Estimate }\end{array}$ \\
\hline 1 &, $809^{\mathrm{a}}$ &, 655 &, 641 & 3,42357 \\
\hline
\end{tabular}

Berdasarkan Tabel 2 di diketahui besarnya independen sedangkan sisanya sebesar $33.9 \%$ Adjusted $\mathrm{R}^{2} \quad$ (R-Square $)=0,809$. Hal ini dijelaskan oleh Variabel-variabel lain diluar menunjukkan bahwa $64,1 \%$ dari variasi variabel variabel yang ada. dependent yang dapat dijelaskan oleh variabel

Tabel 3:

Hasil Pegujian Hipotesis Untuk Uji Parsial Dengan T- Test

\begin{tabular}{|c|c|c|c|c|c|}
\hline \multirow[t]{2}{*}{ Model } & \multicolumn{2}{|c|}{$\begin{array}{l}\text { Unstandardized } \\
\text { Coefficients }\end{array}$} & \multirow{2}{*}{$\begin{array}{c}\text { Standardized } \\
\text { Coefficients } \\
\text { Beta }\end{array}$} & \multirow[t]{2}{*}{$\mathrm{t}$} & \multirow[t]{2}{*}{ Sig. } \\
\hline & B & $\begin{array}{l}\text { Std. } \\
\text { Error }\end{array}$ & & & \\
\hline (Constant) & 22,791 & 9,194 & & 2,479 & ,015 \\
\hline SIA & ,412 & ,053 & ,514 & 7,729 & ,000 \\
\hline SPI & , 148 & ,066 &, 148 & 2,244 & ,027 \\
\hline GOOD GOVERMENT GOVERNANCE &, 105 & ,047 &, 146 & 2,241 & ,027 \\
\hline BUDAYA ORGANISASI & ,824 & , 128 & , 423 & 6,423 & ,000 \\
\hline $\mathrm{R}$ & $\begin{array}{l}=0,809 \\
=0,665\end{array}$ & & & & \\
\hline $\mathrm{R}$ Square $\left(\mathrm{R}^{2}\right)$ & $=0,641$ & & & & \\
\hline Adjust R Square & $=3,42357$ & & & & \\
\hline SEE & & & & & \\
\hline
\end{tabular}

Sumber : data primer yang diolah

Nilai $t_{\text {hitung }}$ untuk variabel Sistem Informasi Akuntansi (X1) sebesar 7,729 dengan tingkat signifikansi sebesar 0,000 (tsig $=0.000$ ) lebih kecil dari nilai $\alpha=0,05$. Dengan demikian, variabel Sistem Informasi Akuntansi(X1) berpengaruh signifikan terhadap kinerja perusahaan $(\mathrm{Y})$ Variabel sistem pengendalian intern (X2) sebesar 2,244 dengan tingkat 
Jurnal Progres Ekonomi Pembangunan (JPEP)

Volume 4, Nomor 1 (2), Tahun 2019

Page: $27-35$

http://ojs.uho.ac.id/index.php/JPEP

signifikansi sebesar 0,027 (tsig $=0,000$ ) lebih kecil dari nilai $\alpha=0,05$. Dengan demikian, variabel sistem sistem sistem pengendalian intern(X2) berpengaruh signifikan terhadap kinerja perusahaan (Y). Variabel Good government governance(X3) sebesar 2,241 dengan tingkat signifikansi sebesar 0,027 (tsig = $0,000)$ lebih kecil dari nilai $\alpha=0,05$. Dengan demikian, variabel Good government governance $(\mathrm{X} 2)$ berpengaruh signifikan terhadap kinerja perusahaan $(\mathrm{Y})$. Variabel sistem budaya organisasi (X4) sebesar 6,423 dengan tingkat signifikansi sebesar 0,000 (tsig $=0,000$ ) lebih kecil dari nilai $\alpha=0,05$. Dengan demikian, variabel budaya organisasi (X2) berpengaruh signifikan terhadap kinerja perusahaan $(\mathrm{Y})$

\subsection{Pembahasan}

Pengaruh Sistem Informasi Akuntansi terhadap terhadap kinerja perusahaan

Hasil pengujian hipotesis menunjukkan bahwa sistem informasi akuntansi berpengaruh signifikan terhadap kinerja perusahaan. Hal ini berarti bahwa semakin adanya sistem informasi akuntansi yang handal dan memenuhi standar teknologisasi informasi modern maka dengan sendirinya akan meningkatkan kinerja karyawan dalam perusahaan dan dapat menciptakan kinerja PT. PLN (Persero) Sub Rayon Wua-Wua dan Benuabenua yang lebih baik dan profesional.

Hasil analisis terhadap variabel sistem informasi akuntansi dengan melihat PCA (principal component analysis) menujukkan bahwa sofware merupakan indikator yang paling dominan mendeskripsikan variabel sistem informasi akuntansi artinya adanya sofware yang memadai seperti sistem operasi, perangkat lunak bahasa programan dan perangkat lunak aplikasi dalam aktivitas operasi akan meningkatkan kinerja perusahaan, sedangkan database merupakan indikator yang paling rendah mendeskripsikan variabel sistem informasi akuntansi artinya database perlu ditingkatkan dari segi kemanan dan efisien dalam penyimpanan data sehingga akan meningkatkan kinerja perusahaan. Namun, untuk mean jawaban responden indikator brainware paling dominan mendeskripsikan sistem informasi akuntansi. Artinya infrastruktur tersebut tidak akan bermanfaat jika tidak didukung oleh sumber daya karyawan. Oleh sebab itu, pengembangan dalam bentuk rekruitmen dan pendidikan dan pelatihan terhadap karyawan dengan sendirinya akan menciptakan brainware yang kompeten dan profesional dalam rangka meningkatkan kinerja PT. PLN (Persero) Sub Rayon Wua-Wua dan Benua-benua. Sedangkan database merupakan indikator terendah menurut responden artinya PT. PLN (Persero) Sub Rayon Wua-Wua dan Benua-benua masih kurangnya kelengkapan penyimpanan data yang memiliki ruang yang efisen dengan tingkat keamanan yang tinggi dan akurat.

Hasil penelitian ini sejalan dengan penelitian yang dilakukan oleh Rosmarini (2016), bahwa sistem informasi pengelolaan keuangan daerah berpengaruh positif dan signifikan terhadap kinerja SKPD Kab. Rokan Hulu., namun penelitian ini tidak sejalan dengan penelitian Soudani (2012) menunjukkan hasil tidak mendukung adanya hubungan positif diantara sistem informasi akuntansi pada kinerja.

Pengaruh sistem pengendalian intern terhadap Kinerja Perusahaan

Pengaruh sistem pengendalian intern terhadap kinerja perusahaan hasil pengujian hipotesis menujukkan bahwa sistem pengendalian intern berpengaruh signifikan terhadap kinerja perusahaan. Hal ini berarti bahwa sistem pengendalian intern sebagai unsur penilaian kinerja dalam mendukung penciptaan kinerja PT. PLN (Persero) Sub Rayon Wua-Wua dan Benuabenua lebik baik.

Hal ini didukung oleh peraturan pemerintah No. 60 tahun 2008, jika didukung dengan lingkungan pengendalian yang kondusif, kegiatan pengendalian yang kontinyu, informasi dan komunikasi yang terkini, pemantauan yang intensif dan selalu dilakukan penilaian resiko, yang dijalankan secara teratur, sistematis dan objektif, serta memenuhi standar pengukuran kinerja yang baik.

Berdasarkan hasil analisis jawaban responden terhadap variabel sistem pengendalian intern dengan melihat PCA (principal component analisys) menunjukkan bahwa kegiatan pengendalian merupakan indikator yang paling dominan mendeskripsikan variabel sistem 
Jurnal Progres Ekonomi Pembangunan (JPEP)

Volume 4, Nomor 1 (2), Tahun 2019

Page: 27-35

http://ojs.uho.ac.id/index.php/JPEP

pengendalian intern, hal ini memiliki kesamaan dengan nilai mean, dimana indikator yang paling dominan mendekripsikan variabel sistem pengendalian intern adalah kegiatan pengendalian. Hal ini menujukkan bahwa PT. PLN (Persero) Sub Rayon Wua-Wua dan Benuabenua telah menjalankan kegiatan pengendalian dan pemantauan dengan baik. Oleh karena itu, kiranya harus lebih sering dalam melakukan pemantauan dan kegiatan pengendalian, dikarenakan dalam pelaksanaanya sistem pengendalian intern mempengaruhi tingkat kinerja perusahaan. Sedangkan dengan melihat PCA (principal component analisys) menunjukkan bahwa lingkungan pengendalian merupakan indikator terendah dalam mendeskripsikan sistem informasi akuntansi, hal ini memiliki kesamaan dengan mean jawaban responden. Artinya perusahaan perlu adanya peningkatkan lingkungan pengendalian dengan merekrut karyawan yang kompeten sesuai dengan kebutuhan perusahaan, tidak memiliki konflik pribadi baik karyawan maupun pelanggan, dan pengambilan keputusan perusahaan serta kebijakan yang diambil harus sesuai prosedur yang telah ditetapkan sehingga mendukung penciptaan kinerja PT. PLN (Persero) Sub Rayon Wua-Wua dan Benua-benua lebik baik.

Di sisi lain, hasil penelitian ini menolak hasil penelitian terdahulu Eo Wetal (2003), bahwa Sistem Sistem sistem pengendalian intern gagal memberikan bukti bahwa mekanisme tata kelola internal dapat berkontribusi pada kinerja perusahaan yang lebih baik.

Pengaruh Good government governance terhadap Kinerja Perusahaan

Hasil uji hipotesis pengaruh good government governance terhadap kinerja PT. PLN (Persero) Sub Rayon Wua-Wua dan Benua-benua menunjukkan bahwa good government governance berpengaruh siginifikan terhadap kinerja perusahaan. Hal ini berarti bahwa good government governance sebagai salah satu persyaratan tata kelola perusahaan yang harus dimiliki dalam mendukung penciptaan kinerja PT. PLN (Persero) Sub Rayon Wua-Wua dan Benuabenua lebik baik.
Sesuai dengan hasil analisis jawaban responden terhadap variabel Good government governance dengan melihat nilai PCA (principal component analysis) menujukkan bahwa responsive merupakan indikator yang paling dominan, artinya semakin baik responsive yang diberikan perusahaan akan meningkatkan kinerja perusahaan. Sedangkan visi startegis merupakan indikator terendah dalam mendeskripsikan good government governance, artinya perusahaan perlu memperhatikan visi misi seperti pada pelayanan publik yang prima, kepuasan pelanggan dan pada peningkatan kinerja perusahaan. Namun, untuk mean jawaban responden indikator keterbukaan paling dominan mendekripsikan Good government governance. Artinya bahwa PT. PLN (Persero) Sub Rayon Wua-Wua dan Benua-benua lebih menekankan kepada keterbukaan informasi yang dibutuhkan konsumen baik lewat media cetak dan elektronik seperti pemadaman lampu. Sedangkan visi strategis merupakan indikator terendah menurut mean jawaban responden, artinya perlu meningkatkan visi starategis terutama dalam kepuasan pelayanan dan peningkatan kinerja sehingga tujuan yang diharapkan tercapai.

Hal ini sejalan dengan penelitian (Dwi Susanto dkk, 2015) yang menyatakan bahwa kualitas penerapan good government governance pada suatu pemerintah daerah provinsi merupakan faktor yang berpengaruhi positif terhadap kinerja pemerintah daerah dalam pemberian layanan masyarakat. Namun penelitian ini tidak sejalan dengan penelitian Febrina dan Arstansi (2017) yang menyatakan bahwa tidak terdapat pengaruh signifikan dari good government governance terhadap kinerja pemerintah daerah.

Pengaruh Budaya Organisasi terhadap Kinerja Perusahaan

Pengaruh budaya organisasi berpengaruh secara signifikan terhadap kinerja PT. PLN (Persero) Sub Rayon Wua-Wua dan Benua-benua, yang artinya budaya organisasi sebagai salah satu persyaratan lingkungan perusahaan yang nyaman dan arif yang harus dimiliki dalam mendukung penciptaan kinerja yang lebik baik.

Berdasarkan hasil analisis jawaban responden terhadap variabel budaya organisasi dengan 
Jurnal Progres Ekonomi Pembangunan (JPEP)

Volume 4, Nomor 1 (2), Tahun 2019

Page: $27-35$

http://ojs.uho.ac.id/index.php/JPEP

melihat nilai PCA (principal component analysis) menujukkan bahwa analisis dan stabilitas merupakan indikator yang paling dominan mendeskripsikan variabel budaya organisasi, artinya budaya organisasi akan berjalan baik jika didukung dengan stabilitas perusahaan terkendali. Jika perusahaan telah mampu mengoptimalkan manusianya baik individu maupun dalam tim dan stabilitas perusahaan terkendali maka akan mencapai hasil yang diharapkan karena mampu melahirkan karyawan yang inovatif serta manajer yang berani mengambil resiko dalam sebuah keputusaan dalam mendukung peningkatan kinerja perusahaan. Sedangkan agresivitas, inovasi dan manajemen resiko merupakan indikator terendah mendeskripsikan budaya organisasi, artinya perusahaan perlu memberikan kepercayaan dan tanggung jawab penuh kepada para manajer maupun karyawan untuk berani ambil resiko.

Namun, ada perbedaan dengan melihat nilai mean jawaban responden, dimana indikator yang paling dominan mendeskripsikan budaya organisasi adalah agresivitas, inovasi dan manajemen resiko, hal ini menujukkan bahwa Budaya organisasi akan menciptakan kinerja dengan lebih memberikan tanggungjawab kepada para manajer maupun karyawan untuk mengambil resiko untuk peningkatan kinerja perusahaan. Sedangkan orientasi hasil, manusia, dan kelompok merupakan indikator yang rendah, artinya PT. PLN (Persero) Sub Rayon Wua-Wua dan Benuabenua perlu meningkatkan kualitas sumber daya manusia dan memperhatikan kesejahteraan pekerja yang diberikan tanggungjawab serta lebih mengutamakan kekompakan tim ketimbang pekerjaan individual untuk meningkatkan kinerja karyawan yang akan berakibat peningkatan kinerja perusahaan.

Hasil penelitian ini didukung (Ida Ayu dan Agus, 2009) Hasil penelitian ini membuktikan bahwa budaya organisasi mempunyai pengaruh positif dan signifikan terhadap kinerja perusahaan, artinya budaya organisasi yang merupakan hasil dari interaksi ciri-ciri kebiasaan yang mempengaruhi kelompokkelompok orang dalam lingkungan organisasinya, akan membentuk suatu persepsi subyektif keseluruhan mengenai organisasi berdasarkan pada faktor-faktor seperti toleransi resiko, tekanan pada tim, dan dukungan orang, persepsi keseluruhan ini akan menjadi budaya atau kepribadian organisasi tersebut yang mampu mendukung dan mempengaruhi kepuasan kerja karyawan dan kinerja perusahaan serta dampak yang lebih besar pada budaya yang lebih kuat. Namun, penelitian ini tidak sejalan dengan penelitian Edward (2016), yang menunjukan budaya organisasi secara parsial berpengaruh negatif terhadap kinerja pegawai di Dispenda Sulut UPTD Todano.

\section{KESIMPULAN}

Berdasarkan hasil penelitian dan pembahasan yang telah diuraikan, maka simpulan dalam penelitian ini adalah sebagai berikut : (1) Sistem Informasi Akuntansi secara parsial berpengaruh signifikan terhadap kinerja PT. PLN (Persero) Sub Rayon Wua-Wua dan Sub rayon Benuabenua (2) Sistem Pengendalian Intern secara parsial berpengaruh signifikan terhadap kinerja PT. PLN (Persero) Sub Rayon Wua-Wua dan Sub rayon Benua-benua (3) Good Government Governance secara parsial berpengaruh signifikan terhadap kinerja PT. PLN (Persero) Sub Rayon Wua-Wua dan Sub rayon Benuabenua. dan (4) Budaya Organisasi secara parsial berpengaruh signifikan terhadap kinerja PT. PLN (Persero) Sub Rayon Wua-Wua dan Sub rayon Benua-benua.

\section{DAFTAR PUSTAKA}

Arsiningsih, Gede Diatmika ., dan Ari Surya. 2015. Pengaruh penggunaan teknologi informasi, efektifitas sistem informasi akuntansi, kepercayaan atas sistem informasi akuntansi, sistem pengendalian intern terhadap kinerja karyawan (Studi Empiris pada Bank Perkreditan Rakyat di Kabupaten Buleleng dan Bangli).Universitas Pendidikn Ganesha, Vol. 3, No. 1.

Ayu, Ida ; Suprayetno, Agus. 2009. Pengaruh motivasi kerja, kepemimpinan dan budaya organisasi terhadap kepuasaan kerja karyawan serta dampaknya pada kinerja perusahaan (Studi Empiris PT. Pei Hai 
Jurnal Progres Ekonomi Pembangunan (JPEP)

Volume 4, Nomor 1 (2), Tahun 2019

Page: $27-35$

http://ojs.uho.ac.id/index.php/JPEP

International Wiratama Indonesia). Manajemen dan Kewirausahaan, Vol.10, No. 2

Bambang Pamungkas. 2012. Pengaruh Penerapan Akuntansi Publik Dan Kualitas Peraturan Perundangan Terhadap Kualitas Laporan Keuangan Dan Implikasinya Terhadap Akuntabilitas Kinerja Instansi Pemerintah. Volume 12, No. 1.

Febrina, Lastiar; Widyaningsih, Aristanti. 2017. Pengaruh Good Governement Governance dan ukuran legislatif terhadap kinerja pemerintah daerah (Studi Kasus Empiris pada Pemerintah Provinsi Indonesia. Akuntansi.Vol.9, No. 1.

Indriawaty, Desy. 2015. Pengaruh Sistem Informasi Akuntansi dan Motivasi Kerja terhadap Kinerja Karyawan (Studi pada PT. PLN (Persero) Distribusi Jawa Barat dan Bandung). Fakultas Ekonomi, Universitas Pasundan, Bandung.

Koesmono, H. Teman. 2005. Pengaruh Budaya Organisasi Terhadap Motivasi dan Kepuasan Kerja serta Kinerja Karyawan Pada Sub Sektor Industri Pengolahan Kayu Skala Menengah Di Jawa Timur. Jurnal Manajemen dan Kewirausahaan,Vol 7,No 2.

Maabut, Edward S. 2016. Pengaruh kepemimpinan, orientasi kerja, dan budaya organisasi terhadap kinerja pegawai (Studi Empiris pada Dispenda Sulut UPTD Tondan). Fakultas ekonomi dan bisnis, Universitas Sam Ratulangi.Vol.16, No. 1.

Peraturan Menteri Dalam Negeri Nomor 13 Tahun 2006 tentang Pedoman Pengelolaan Keuangan Daerah.

Peraturan Pemerintah No. 60 tahun 2008 tentang Sistem Pengendalian Internal Pemerintah.

Rosmarini, Tri. 2016. Pengaruh Pengawasan Intern, Sistem Anggaran Berbasis Kinerja dan Sistem Informasi Pengelolaan Keuangan Daerah terhadap Kinerja Satuan Kerja Perangkat Daerah (Studi Empiris pada SKPD Kabupaten Rokan Hulu). JOM Fekon, Vol. 3, No. 1.

Rubino, Michele; Vitolla, Filippo; dan Garzoni, Antonello. 2017. The Impact of an IT Governance Framework on the Internal Control Environment. Record Management Journal. Vol. 27, No. 1.
Soudani, Siamak Nejadhosseini. 2012. The Usefulness of an Accounting Information System for Effective Organizational Performance. School of Accounting and Management, Islamic Azad University U.A.E. Branch. International Journal of Economics and Finance.

Susanto, Azhar. 2013. Sistem Informasi Akuntansi, Struktur Pengendalian Resiko, Pengembangan. Bandung : Lingga Jaya.

Susanto, Dwi ; Angreani, dian; Rachmawati, Yunaita. 2015. Pengaruh good governance terhadap kualitas pemberian layanan publik. Vol.12, No. 2.

Undang-Undang No 25 tahun 2009 tentang Pelayanan Publik 